Raymond Mercier

Southampton University, Southampton, SO9 5NH, England.

ABSTRACT The canons of Sanskrit astronomy depend on mean motions which are normally postulated to refer to the central meridian of Ujjain. The present work is a statistical analysis of these mean motions designed to discover the optimum position of the meridian, by comparison with modern mean motions. This follows earlier work done by Billard in determining the optimum year. The results confirm that from the time of Aryabhața all the canons were referred to meridians lying well within India, and in many cases clearly identifiable with Ujjain within the statistical bounds.

1. INTRODUCTION

The general idea underlying the research which is summarised in the present paper is hardly original, and indeed is a direct development of that employed so successfully in Roger Billard's 1'Astronomie Indienne (Billard (1971)). The medieval mean longitudes of Sun, Moon and planets are compared directly with the corresponding modern means, and the differences are treated by the method of least squares in order to determine values of the year and of the meridian to which the medieval longitudes are referred.

In Billard's researches the meridian was always assumed to be that passing through Ujjain, the central meridian repeatedly referred to in Sanskrit sources. In this way he was able to $f i x$, within narrow limits as a rule, the year when the Indian mean longitudes best agreed with the true configuration.

In the present work not only the year, but also the meridian are allowed to vary in the search for the best fit. There are also improvements in the modern parameters, taking advantage of quite recent developments, and besides the statistical control follows more closely the formal method of least squares.

Apart from a natural confirmation of Billard's results for the optimum year, we have a series of results for the optimum meridian showing that it always lies in India, indeed generally near to Ujjain (1ongitude 75;46 East of Greenwich). This reinforces very well Billard's general conclusion that with the Sanskrit canons we are presented with a continuous millenium of observational astronomy in India.

Al1 of the canons cited by Billard have been analysed in this way, as well as a number of others, but here there is room only to present a few particularly important ones. 
2. MEAN LONGITUDES AND DEVIATIONS

Let the modern mean longitudes be denoted $L_{i}(t)$, where the suffix runs from 1 to 9:
1. Sun
2. Moon
5. Mercury
3. Lunar apogee
6. Venus
4. Lunar node
7. Mars

9. Saturn

Al1 these are tropical longitudes. The precise numerical expressions are those now to be employed in the national ephemerides, following an IAU recommendation (Francou, e.a., 1983). These expressions are functions of Terrestrial Dynamical Time (TDT) which differs from Universal Time by the quantity $\Delta \mathrm{T}$, which allows for the changes in the rate of rotation of the earth; this includes both a steady rate of decrease, and fluctuations. A satisfactory expression for the steady part of $\Delta T$ depends necessarily on ancient eclipse records, and this calculation is in no way as accurate as that determining $L_{i}$. For many years a formula for $\Delta \mathrm{T}$ which was determined by Spencer Jones (1939) has been used, although there are theoretical objections (van der Waerden (1961)) to its derivation. Many new formulae have been derived, but they do not agree especially well among themselves, nor do they meet the objections brought by van der Waerden against the older formula. Naturally the uncertainty in the value of $\Delta \mathrm{T}$ appears directly in the meridian which we determine, but it is unlikely that further revisions of $\Delta T$ would lead to alterations in the meridian of more than a few minutes of arc.

In this paper the expressions for $L_{i}(t)$ include terms as far as $t^{3}$ (as taken from references 1 isted by Francou, e.a., (1983)), and in addition a large number of trigonometrical terms expressing the various perturbations (1). These are included for Venus, the Sun, Mars, Jupiter and Saturn, but are effectively important only for the last two, which are affected by the well known resonance.

The medieval mean longitudes $\lambda_{i}(t)$, where $t$ is simply the Universal Time, are linear expressions. In most cases, the canons which we analyse are already included in Billard's survey, and there one will find the numerical details. As a general rule the Sanskrit canons define sidereal longitudes.

\section{THE METHOD OF LEAST SQUARES}

We now change the notation slightly, so that $t$ denotes the Universal Time, and TDT as required for $L_{i}$ will be $t+\Delta t$, with $\Delta t$ provided by the Spencer Jones formula, faute de mieux. The deviation between the modern and the medieval mean longitudes is defined as

$$
D_{i}(t, \phi)=\lambda_{i}(t-\phi / 360)-L_{i}(t+\Delta t)
$$

where $\phi$ is the longitude of the meridian East of Greenwich. 
The method of least squares will be used to determine jointly the optimum estimates to and $\phi_{0}$. For this purpose we must postulate 'true' values of $D_{i}(t, \phi)$, which may be done in two ways. If $\lambda_{i}$ are tropical longitudes, such as we may calculate from the Sanskrit canon when we are also given a model of precession, then the 'true' value of $D_{i}$ is zero, and then we would seek the minimum of the sum

$$
Q=\sum_{I} D_{i}^{2}
$$

where $I$ is a selection of values of $i$. In this case we say that the deviations are 'absolute'. On the other hand, if $\lambda_{i}$ is sidereal, the 'true' value of $D_{i}$ would depend on the rate of precession together with an unknown constant. In this case therefore, which we refer to as 'relative', we can only take the mean of the set $D_{i}$ as the true value, and calculate the minimum of

$$
Q=\sum_{I}\left(D_{i}-\left(\sum_{I} D_{i}\right) / N\right)^{2}
$$

where $\mathrm{N}$ is the number of deviations included. When the deviations are relative, the number of random variables is then $N-1$. Let I be indicated by a sequence of $1^{\prime} \mathrm{s}$ or $0^{\prime} \mathrm{s}$, indicating whether a particular value of $i$ is included or not: thus (1101 00000) would indicate that the Sun, Moon and lunar node only are included. Further the set I will be augmented by an initial 1 or 0 to indicate whether we are concerned with absolute or relative deviations, respectively. With each determination of the year and the meridian, then, we associate a statistic $I$, such as $(01101$ 0000). This is the same symbol as used by Billard.

The method of least squares has been explained in a suitably general and clear way by van der Waerden (1967). In the following only the briefest summary of the application is possible.

If we write in the neighbourhood of the minimum

$$
Q=h_{11}\left(t-t_{0}\right)^{2}+2 h_{12}\left(t-t_{0}\right)\left(\phi-\phi_{0}\right)+h_{22}\left(\phi-\phi_{0}\right)^{2}+Q_{0} \text {, }
$$

then the estimate of the variances of $t_{0}$ and $\phi_{0}$ are $s_{t}{ }^{2}$ and $s_{\phi}{ }^{2}$ :

$$
\begin{aligned}
& s_{t}{ }^{2}=\frac{Q_{0}}{n-r} \frac{h_{22}}{h_{11} h_{22}-h_{12}{ }^{2}} \\
& s_{\phi}{ }^{2}=\frac{Q_{0}}{n-r} \frac{h_{11}}{h_{11} h_{22}-h_{12}{ }^{2}}
\end{aligned}
$$

where $n$, the number of random variabless, is one less than the number of $I^{\prime} s$ in the symbol $I$. Moreover if $\tilde{t}$ and $\tilde{\phi}$ and are the true 
values, then

$$
\left(t_{0}-\tilde{t}\right) / s_{t}, \quad\left(\phi_{0}-\tilde{\phi}\right) / s_{\phi}
$$

follow the Student t-distribution with $n-r$ degrees of freedom. We may thereby assign confidence limits to the estimates $t_{0}$ and $\phi_{0}$, as obtained from the minimum value $Q_{0}$. If $n-r$ were large, then $t_{0}$ would have a probability of 0.682 of lying within one standard deviation of the true value. We use the Student distribution in this way to find the equivalent range for a probability of $68 \%$.

If $\sigma$ is the standard deviation of individual deviations $D_{i}$, then $s^{2}=Q_{0} /(n-r)$ is an unbiased estimate of $\sigma^{2}$. Moreover $Q_{0} / \sigma^{2}$ has a $x^{2}$ distribution with $n-r$ degrees of freedom, so that one may $f$ ind limits of confidence for $\mathrm{s}^{2} / \sigma^{2}$ at a given level, in our case chosen to be $95 \%$.

There are canons, such as that known from Lalla's 'Sişyadhivroddhidatantra, in which the year cannot be effectively determined. In that case it is more practical to $f i x$ in advance the value of $t$, and to apply the present methods to determine $\phi_{0}$ alone, in which case $r=1$, in the above expressions.

\section{DISCUSSION OF THE RESULTS}

4.1 General remarks

For each of the canons, and each of the statistics $I$, the results are given in the table below, Section 5 .

These results for the determination of the meridian are satisfying in that they Iie in every case in India. Nevertheless, they differ to a varying extent from the meridian of Ujjain. There are two obvious ways in which this may occur, for we may have either an error on the part of the author of the canon, or it may have been the case that the observations were established for some other meridian, without any attempt to reduce them to that of Ujjain. No doubt both these reasons have some degree of application.

A third possibility is that the discrepancy might arise from the equation of time. I have indicated elsewhere, however, (Mercier 1985 ), that while difficulties would arise because of the way in which the equation is defined in Greek, Arabic and Latin usage, in Sanskrit usage the equation takes positive and negative values symmetrically, so that there the Mean Solar Time would be the same as that used now. This would seem to be the case from the beginning of Sanskrit astronomy, since Varahamihira, in his discussion of the Sūryasiddhānta (Pañcasiddhāntikā IX,9) indicates an approximate rule for the equation.

4.2 The Romaka Siddhānta

The earliest of the canons in this survey is the Romaka 
Siddhānta, based on parameters given by Varāhamihira in the Pañcasiddhāntikā (VIII, 1-8). The deviations are limited in use, since the lunar apogee and node are not in good agreement with the Sun and Moon. Therefore only the statistic $(11100$ 00000) is available, and we can only find a year and meridian such that $Q_{0}=0$, since $n=r$. Therefore no statistical bounds can be assigned to the year and meridian. Nevertheless the results are very interesting, especially in regard to the meridian $86 ; 40$. This is considerably too large for one to suppose that Indian observations were responsible for the canon, but if we recollect the longitude difference of $56 ; 30$ between Alexandria and Ujjain, according to Ptolemy's Geography (IV,5,9; VII, 1,63)

$$
\begin{array}{lr}
\text { Alexandria } & 60: 30 \\
\text { Ujjain } & 117 ; 0,
\end{array}
$$

we see that the Romaka canon might very well have been transferred to Ujjain, by means of such presumed positions, from a Greek source at a meridian around 30;0, which is indeed the correct longitude of Alexandria. The name Romaka, and the use of the year $365.24666 \ldots$, indicate clearly enough the dependence on a Greek source. The longitude difference 60;0 between Yavanapura (Alexandria) and Ujjain is entailed by a remark concerning two astronomers of the time, Lātācārya and Simhācārya (Pañcasiddhāntikā, XV, 17-20) (2).

\section{3 Āryabhaţa}

In the list of results in Section 5 one naturally groups together the next three canons, those of the Āryabhatiya, and the two from Varāhamihira's Pañcasiddhāntikā: the Sūrya Siddhānta, and the emendation to the planetary parameters of that work defined in XVI, 10-11. We know that only the Aryabhațiya is accurate in the case of Jupiter, so that $D_{8}$ must be omitted from the statistic for the other two. That much is clear from Billard's analysis of the deviations, and the use of the most recent modern ephemerides does not alter the position. The use of the new ephemerides has however an extremely interesting consequence, for the optimum year is now very nearly equal to 499 A.D., incomplete. That year is singled out by Āryabhața (Āryabhațiya III,10) although he contents himself with merely telling us that he was then aged 23, so that one has never been altogether clear as to its astronomical significance. This point is however distant 3600 years, quite precisely, from the Kaliyuga, so that it can hardly be doubted that it had, for Indian astronomy, some decisive importance. When the older ephemerides of Newcomb, Brown, etc., are used to obtain the year and the meridian, we obtain

$$
\left(\begin{array}{lll}
0 & 1111 & 01111
\end{array}\right) \quad 507.6 \pm 4.05 \quad 79 ; 8 \pm 1 ; 24 \text {. }
$$

It is now apparent that although with the new parameters, no great change results, nevertheless the results point more clearly than before to the year A.D. 499 as that year to which Aryabhața referred observational results which were collected around that time. It is not clear why exactly that year was chosen, although it may have been believed by 
Arryabhața that the precessional correction vanished then. In any case, how can one avoid the conclusion that the Kaliyuga, 3600 years earlier was defined and fixed as a direct consequence? The two versions of that epoch, Sunrise and Midnight, are fixed exactly, so that in terms of the related canons, Āryabhațīya, and the Sūryasiddhānta, respectively, 3600 sidereal years separate the epoch from Noon 499 March 21. The enduring use of the Kaliyuga in all the following centuries testifies to the decisive importance of the work of Aryabhata in the history of Indian astronomy (3).

The statistical results for the emendation to the Surryasiddhanta show remarkably that when some later astronomers established it, the effect was to improve the accuracy at the epoch year A.D. 499. We now have 498. 1 for the Sun and Moon alone, and 499.1 with the planets included. It is as if those responsible had access to the observational data, and were able to make better use of it so as to obtain even more accurate longitudes for the selected epoch year. Is it not wonderful in any case, that the most modern and accurate parameters help us to discover and appreciate better than ever before the very accurate Indian observations made nearly 1500 years ago?

\subsection{The canon of Lalla}

The canon taken from a set of emendations given to us by Lalla is singularly interesting, because unlike most others, indeed all others preceding it, it is in good agreement with observations over a long period. This means that one cannot determine the year by the method of least squares, although other considerations such as the form of the emendations, lead one to associate it with the late ninth century. The determination of the meridian, however, is secure, and indeed safer than in some other cases, precisely because the optimum meridian is so insensitive to the choice of year. One is struck in this case by the close approximation of the optimum meridian to that of Ujjain, reinforcing the view that the canon was the product of outstandingly careful work. In the diagram there are shown the graphs of $\sigma$ against $\phi$ for the selection of statistics given in Section 5 .

\subsection{The Drgganita}

This work was composed in 'Saka 1353 (A.D. 1431-2), by Parameśvara, an astronomer of Kerala, and constitutes the exposition of the Drrk ('Observational') system (Sarma (1963)). It is produced by a set of emendations applied to that version of the Süryasiddhanta on which Parameśvara wrote his commentary (Shukla (1957)), or equivalently, to the Karana Tilaka of Vijayanandin, ca. 950 (Rizvi (1963)). The emendations of the solar and lunar parameters were derived from eclipses of Sun and Moon observed by Parameśvara in the period 1398 1432 inclusive, from which he determined mean longitudes referred to the date with ahargana 1651700 (essentially 4522 sidereal years), at Sunrise, which is A.D. 1421 March 29. The text in which the dates and circumstantial details of the eclipses are given has been edited by Sarma (1966). For that date he found the following: Sun 0,13;0, Moon 10,$4 ; 6$, Apogee 3,$9 ; 57$, Node 4,$23 ; 55$. These figures are most interesting 
MAIO16 AT SOTONVM AT 20:00:28 ON 16/02/1987

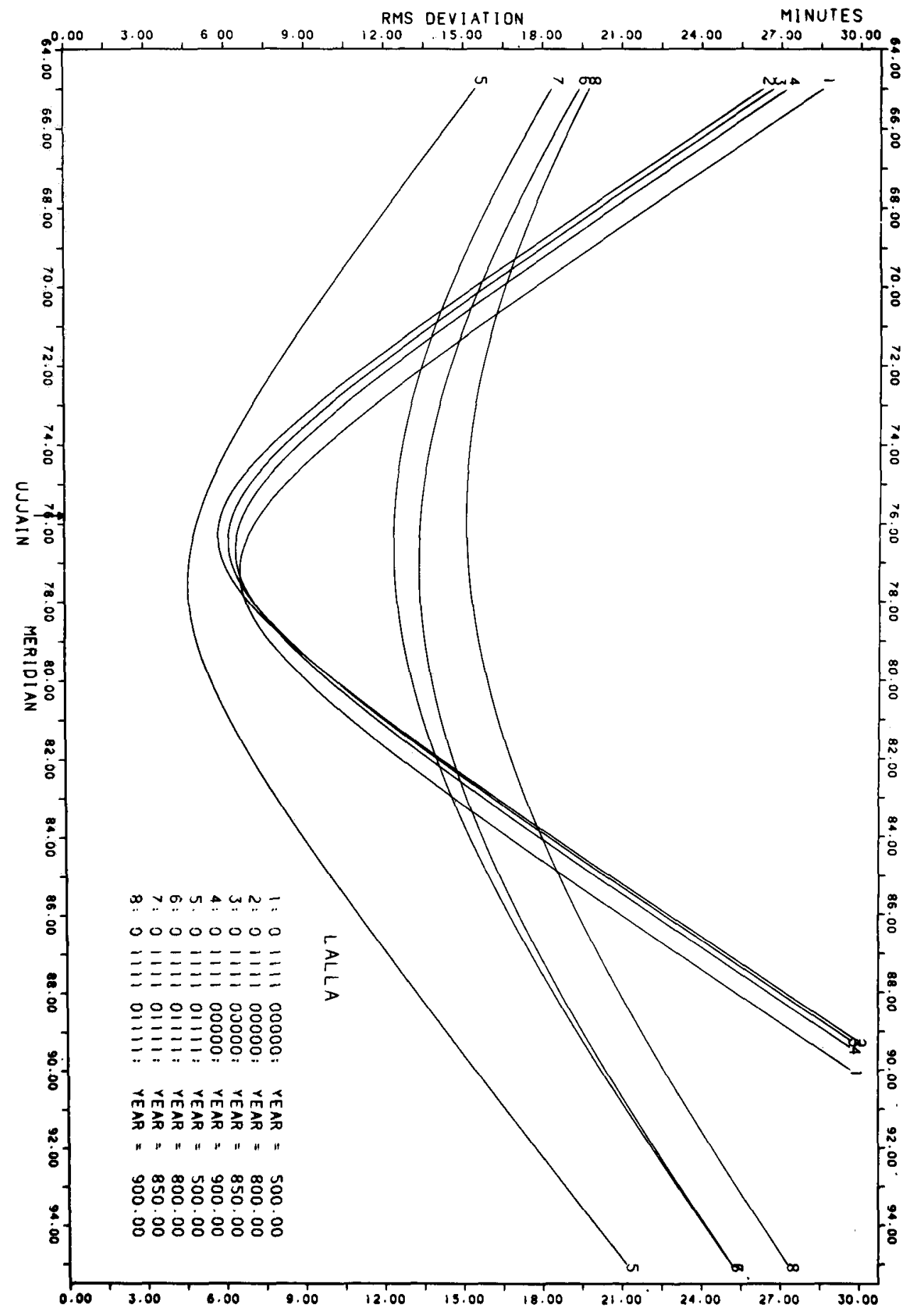


in that the longitude of the Sun is tropical, while the others are sidereal; that is the night-time observations are sidereal, the daytime tropical. Should we not see here an illustration of the paradigm of observation and tabular correction such as had been used throughout Indian astronomy, beginning with Äryabhața?

The present methods applied to the eclipse deviations confirm well enough the documented circumstances, the year near 1421 , and a meridian appropriate to Kerala $(76 ; 30)$ or perhaps Ujjain, for we cannot be certain whether Parameśvara reduced his parameters to the normal meridian.

\subsection{Sphuţanirnayatantra}

This work, by the Keralite astronomer Acyuta (1550-1620)

was edited by Sarma (1974), and is of interest here because it is the one example known to me in Indian texts of a change of meridian. For, there is a short tract in another Malayalam MS, published as Appendix 5 by Sarma, in which the mean longitudes differ only by a shift of meridian, exactly 6.804 degrees Westward. Thus the respective meridians are approximately 80.5 and 74 , neither of which however is suited to southern India. Moreover the accuracy is generally best in the thirteenth century, so one might infer that Acyuta obtained the canon from an earlier astronomer who lived further north.

\section{TABLE OF RESULTS}

The quantities $g$ iven after the statistic are respectively, $\mathrm{t}_{0}, \phi_{0}$, with their standard deviations; $\sigma$, in minutes; the mean deviation at the point $\left(t_{0}, \phi_{0}\right)$; and the year and standard deviation for the meridian of $\mathrm{Ujjain}$. In the case of those canons for which the year cannot be determined, the statistics concerning the meridian are given for certain preassigned values of the year. In all cases the year given is 'complete'.

Romaka Siddhānta

1110000000

$400.0 \quad 86 ; 40$

Sūrya Siddhānta

0111100000

498.1 $\pm 31.67 \quad 77 ; 19 \pm 6 ; 25 \quad 10.67 \quad 0 ; 14 \quad 493.8 \pm 14.7$

$0 \quad 111101101$

$502.0 \pm 5.41 \quad 77 ; 28 \pm 1 ; 54 \quad 5.00 \quad 0 ; 11 \quad 501.3 \pm 5.23$

Āryabhața

0111100000

$\begin{array}{lllll}498.1 \pm 31.67 & 77 ; 20 \pm 6 ; 01 & 10.67 & 0 ; 14 & 494.3 \pm 15.82 \\ 0111101111 & & & & \\ 502.1 \pm 5.10 & 77 ; 38 \pm 1 ; 45 & 4.70 & 0 ; 12 & 501.7 \pm 5.13\end{array}$


Pañcasiddhãntikā

0111100000

$498.1 \pm 31.67$

0111101101

$77 ; 19 \pm 6 ; 25$

$10.67 \quad 0 ; 14$

$493.8 \pm 14.7$

499. $1 \pm 6.84$

$77 ; 16 \pm 1.49$

$4.720 ; 14$

$497.8 \pm 6.36$

La1la

$0 \quad 111100000$

500

800

$77 ; 11 \pm 2 ; 40$

$6.6 \quad 0 ; 5$

$76 ; 11 \pm 2 ; 20 \quad 5.8 \quad-4 ; 47$

850

$76 ; 23 \pm 2 ; 30$

$6.1-5 ; 35$

900

$76 ; 35 \pm 2 ; 36$

$6.4-6 ; 24$

0111101111

500

800

$77 ; 23 \pm 1 ; 43$

$77 ; 00 \pm 4 ; 58$

$4.6 \quad 0 ; 8$

$13.33-4 ; 44$

$76 ; 23 \pm 4 ; 37$

$12.38-5 ; 34$

900

$75 ; 47 \pm 5 ; 38$

$15.1-6 ; 24$

Karana Tilaka

0110101011

$951.6 \pm 8.51$

1110101011

$81 ; 26 \pm 3 ; 35 \quad 9.4 \quad-6 ; 59 \quad 950.7 \pm 10.43$

$955.4 \pm 17.45$

$87 ; 22 \pm 6 ; 34$

$19.73 \quad 0 ; 8$

$955.5 \pm 20.58$

Drgganita

0111100000

$1424.5 \pm 27.19$

$77 ; 19 \pm 6 ; 6$

$9.9-14 ; 40$

$1420.5 \pm 12.30$

Sphuţanirnayatantra

0111100110

1250

1350

$80 ; 47 \pm 1 ; 45$

$81 ; 35 \pm 1 ; 53$

$81 ; 47 \pm 5 ; 39$

$4.64-12 ; 3$

$5.00-13 ; 39$

1550

$14.99-16 ; 55$

6. SELECTED CANONS

There are three canons which are not given by Billard, and which are not readily available elsewhere.

6.1 Romaka Siddhānta

Epoch A.D. $5 \overline{05 \text { March } 21 \text { Sunr }}$ ise (1905588.75)

Sun

$(150 t-65) / 54787$ revs

Moon

$(38100 t-1984) / 1040953$ revs

Lunar argument

$(110 t+664) / 3031$ revs

Lunar node

$-(24 t+56278) / 163111$ revs

The time $t$ is measured in days from the epoch. These results are taken from unpublished work on R. Billard. 


\subsection{Sphuțanirnayatantra (a)}

Sphuțanirnaya tulyagrahamadhyamānayanam (b)

Epoch 588465.75 (Kaliyuga Sunrise)

Period (Kalpa) 1577917517019 days

$\begin{array}{lccr} & \text { radix (a) } & \text { radix }(b) & \text { yugabhagana } \\ \text { Sun } & 0 ; 0 & 0 ; 1,7,4 & 4320000000 \\ \text { Moon } & 4 ; 21,21,36 & 4 ; 36,18,7 & 57753321009 \\ \text { Apogee } & 118 ; 50,9,36 & 118 ; 50,17,11 & 488123229 \\ \text { Node } & 201 ; 18,43,12 & 201 ; 18,39,36 * & -232297832 \\ \text { Mercury } & 350 ; 12,28,48 & 350 ; 17,7,14 & 17937072112 \\ \text { Venus } & 35 ; 6 & 35 ; 7,49,1 & 7022270775 \\ \text { Mars } & 348 ; 9,21,36 & 348 ; 9,57,15 & 2296862959 \\ \text { Jupiter } & 15 ; 15,50,24 & 15 ; 15,56,3 & 364172296 \\ \text { Saturn } 340 ; 22,48 & 340 ; 22,50,17 & 146626695\end{array}$

* The text as edited gives $204 ; 18,39,36$, which must be emended to $201 ; 18,39,36$.

The radices (a) are equal to 0.4569 bhagana, which recalls the construction used in the Brăhmasphuțasiddhänta, which has 0.4567 bhagana as a general formula for its radices.

Both the texts (a) and (b) were edited by Sarma (1974), who gives (b) in Appendix 5.

\subsection{Karana Tilaka}

The parameters are identical to those of the modern Sūrya Siddhānta in the version given by Billard, except for two yugabhagana:

Lunar apogee 488211 in place of 488203

Lunar node -232234 in place of -232238

See Rizvi (1963).

\section{NOTES}

(1) The trigonometrical terms are available from the Bureau des Longitudes, Paris.

(2) I am indebted to some important unpublished work on this canon by Roger Billard, who proposed the interpretation of the meridian $86 ; 40$.

(3) This proposal, that the Kaliyuga originates strictly with Aryabhața, contradicts van der Waerden's conclusions (1978 and 1980). $\mathrm{His}$ argument begins by observing that $\mathrm{Ab} \overline{\mathrm{u}} \mathrm{Ma}^{<}$shar made use of the Kaliyuga as the date of the Deluge, and that he also made use of 'Persian' tables. If this only meant the $2 \bar{i} j-i$ Shāh in the midsixth century, there would be no problem, but van der Waerden argues for a Hellenistic dependence, via an earlier Persian system. 


\section{REFERENCES}

Billard, R. (1971). L'Astronomie Indienne, Investigation des texts Sanskrits et des données numériques. Paris: École Française d'Extrême-Orient.

Francou, G., Bergeal, L., Chapront, J., and Morando, B. (1983). Nouvelles ephemerides du Soleil, de la Lune et des planetes. Astronomy and Astrophysics 128 124-139.

Mercier, R. (1985). Meridians of Reference in Pre-Copernican Tables. Vistas in Astronomy 28 23-7.

Rizvi, Sayyid Samad Husain (1963). A Unique and Unknown Book of al-Beruni, Ghurrat-uz-Zijat or Karana Tilakam. Islamic Culture (Haidarabad, India) 1963 (Apr., July, Oct.) 1964 (Jan., July) 1965 (Jan., Apr.).

Sarma, K.V. (1963). Dṛggaṇita of Parame'svara, critically edited with Introduction. Hoshiarpur, Punjab: VVRI.

Sarma, K.V. (1966). Grahaṇanyāyadīpikā of Paramésvara, critically edited with a translation. Hoshiarpur, Punjab: VVRI.

Sarma, K.V. (1974). Sphuţanirnaya-Tantra of Acyuta, with autocommentary, critically edited with Introduction and ten appendices. Hoshiarpur, Punjab: VVRI.

Shukla, K.S. (1957). The Sūryasiddhānta edited with the commentary of Paramesvara. Lucknow: Lucknow University.

Spencer Jones, H. (1939). The rotations of the earth, and the secular accelerations of the Sun, Moon and planets. Mon. Not. R. astr. Soc. 99 541-558.

van der Waerden, B.L. $(\overline{1961)}$. Secular Terms and Fluctuations in the Motions of the Sun and Moon. Astronomical J. 66 138-147. van der Waerden, B.L. (1967). Statistique Mathematique. Paris: Dunod. van der Waerden, B.L. (1978). The Great Year in Greek, Persian and Hindu Astronomy. Archive for History of Exact Sciences 18 359-384.

van der Waerden, B.L. (1980). The Conjunction of 3102 B.C. Centaurus 24 117-131. 


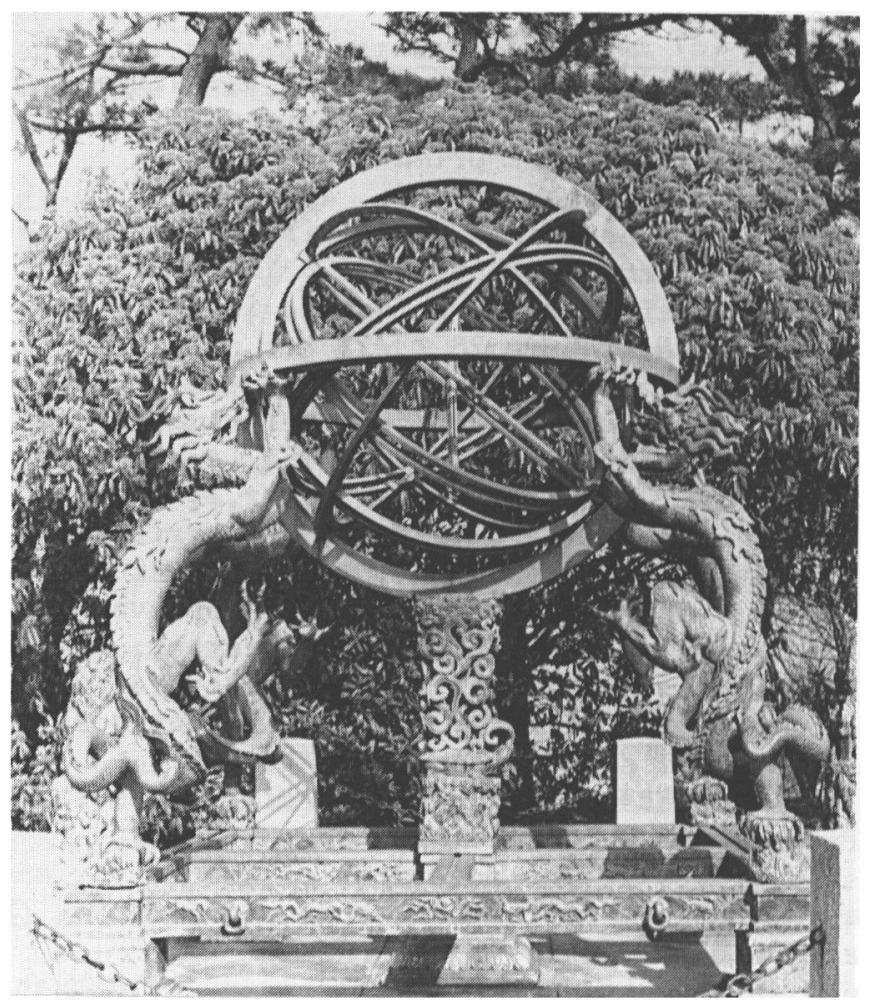

Armilary Sphere. It is an ancient China's cast-bronze astronomical instrument, engraved with excellent artistry. It has an observing tube, which is used mainly for determining the equatorial coordinates and the longitudes and horizontal coordinates of celestial bodies. It was made in 1437 , the second year of the Zheng-Tong Reign of the Ming Dynasty. 